\title{
Correction to: Trading Ontology for Ideology (and Vice Versa)
}

\section{Martin Vacek ${ }^{1}$}

Published online: 17 January 2020

(C) Springer Nature B.V. 2020

\section{Correction to: Acta Analytica https://doi.org/10.1007/s12136-019-00411-2}

The original version of this article unfortunately contains incorrect argument in section 5 and the corrected section headings.

The corrected argument in section 5 should be

1. Some debates in metaphysics pursue ontological and ideological parsimony. (assumption)

2. If debates pursue ontological and ideological parsimony, they turn out to be difference minimising. (assumption)

3. Difference minimising results in epistemic underdetermination. (Bennett's result)

4. Some debates in metaphysics are difference minimising. (MP, 1, 2)

5. Some debates in metaphysics are epistemically underdetermined. $(3,4)$

6. Some debates in modal metaphysics pursue ontological and ideological parsimony. (Assumption)

7. Some debates in modal metaphysics are difference minimising. $(6,2)$

8. Some debates in modal metaphysics are epistemically underdetermined. $(7,3)$

9. MD does not pursue ontological and ideological parsimony. (Divers)

10. MD is not subject to difference minimization. $(9,2)$

Conclusion

MD should be preferred to theories that pursue ontological and ideological parsimony and are subject to difference minimisation.

The online version of the original article can be found at https://doi.org/10.1007/s12136-019-00411-2

Martin Vacek

martinvacekphilosophy@gmail.com

1 Institute of Philosophy, Slovak Academy of Sciences, Klemensova 19, 81109 Bratislava, Slovakia 
Premises 1, 2 and 3 have been defended by Effingham and/or Bennett, and thus I will not discuss them further. On the other hand, premises 6 and 7 are crucial to my argument. Although premise 6 is usually taken to be true in the literature on possible worlds, its connection to premise 2 and their mutual consequence, premise 7, are considered problematic. I will therefore discuss them in turn.

The corrected section headings should be

6 Modal Realism vs. Magical Ersatzism

$7 \mathrm{MR}, \mathrm{MD}$ and the Incredulous Stare

8 Magical Ersatzism and the Dilemma

9 Magical Ersatzism: Upplaying Explanatory Power vs. Downplaying Ideology

10 Conclusion

Publisher's Note Springer Nature remains neutral with regard to jurisdictional claims in published maps and institutional affiliations. 